\title{
Constraints faced by farmers of Haryana state in adoption of masumbi (Citrus sinensis) cultivation
}

\author{
Pawan Kumar*, P. S. Shehrawat, Anil Kumar Rohila and B. S. Ghanghas and Ashok Kumar ${ }^{1}$ \\ Department of Extension Education, CCS Haryana Agricultural University, Hisar-125004 (Haryana), INDIA \\ ${ }^{1}$ Directorate of Extension Education, CCS Haryana Agricultural University, Hisar-125004 (Haryana), INDIA \\ *Corresponding author. E-mail: pawanbhuka126@gmail.com \\ Received: August 29, 2015; Revised received: February 15, 2016; Accepted: May 16, 2016
}

\begin{abstract}
The study focused on the constraints faced by farmers of Haryana state in adoption of masumbi (Citrus sinensis) cultivation. The study was conducted in Bhiwani district. The constraints as perceived by the respondents were measured by the scores on the basis of magnitude of the problems. Constraints were categorized into inputs, marketing, production, technical and psychologicalconstraints. While analyzing overall constraints as perceived by farmers the findings revealed that high price of insecticides/pesticides (weighted mean score 2.25), non-availability of inputs at proper time (1.13), absence of agro-processing units (2.05), no support price (1.86), aberrant climatic conditions (1.99), unawareness about proper and balanced fertilizer application and time of application (1.99), lack of guidance of post-harvest technology (1.95), lack of knowledge of current advances in fruit cultivation (1.34), longer time taken in fruit bearing (1.51) and orchard maintenance(1.34) etc. were major constraints faced by the farmers.
\end{abstract}

Keywords: Constraints, Cultivation, Fruit, Masumbi

\section{INTRODUCTION}

India is the second largest producer of fruits after China, with a production of 88977 thousand million tonnes of fruits from an area of 7216 thousand hectares. Now a day's citrus has become a major commercial fruit crop in the Haryana state. Citrus has vigorous growth and heavy yield with favorable growing conditions in orchards and sufficient irrigation. According to 2014 statistics, in Haryana the citrus is grown on an area of 19.4 thousand ha with production 235.4 thousand MT (Anonymous, 2014).

Today fruits and vegetable farming as a diversified farming is important to generate employment round the year, supplement farm economy and to earn foreign exchange also by enhancing the export. As well as fruits play an important role in human nutrition offer diversity indirect, ecological sustainability and fight against hunger. It is generally stated that the living standard of people can be judged by the production as well as consumption of fruits.

Keeping in view the above facts and importance of this fruit crop for the country as a whole and Haryana state in particular, the study was conductedto find out constraints faced by farmers of Haryana state in adoption of masumbi (Citrus sinensis) cultivation.

\section{MATERIALS AND METHODS}

To collect the primary data on prospects of Citrus sinensis cultivation perceived by farmers, the respondents were selected with multistage sampling. Among fruit growing states of India, Haryana was purposively selected being emerging state in Citrus cultivation as well as direct access to the investigators. From state, Bhiwani district was also selected purposively because it fall in Southern Haryana cluster of NHM scheme for development of citrus cultivation due to suitable climate and soil requirement along with maximum area under drip irrigation. Further 3 blocks viz. Dadri, Badhra and Loharu were selected purposively. From each block 40 farmers were selected randomly, making a total of 120 respondents. The data were selected with the help of well-structured and pre-tested interview schedule. The schedule consisted 11 items like better market facilities, better fruit quality, better economic returns etc. The responses were obtained on three-point continuum scale in case of prospects (More bright, somewhat bright and not at all bright) and scores were given as 3,2 and 1, respectively. After that frequency was multiplied with the score $(3,2$ or 1$)$ and total weighted score was obtained and total weighted score was divided by total respondents (120) for weighted mean score. In case of mean score which is expressed in percentage, total cumulative frequency was divided by total possible score. The data were analyzed with frequency, weighted frequency, cumulative frequency, weighted mean score, mean score expressed and rank order. 
Table 1. Constraints related to inputs $(n=120)$.

\begin{tabular}{|c|c|c|c|c|c|c|c|c|}
\hline $\begin{array}{l}\text { S. } \\
\text { N. }\end{array}$ & Constraints & $\begin{array}{l}\text { Constraint } \\
\text { level }\end{array}$ & Frequency & $\begin{array}{l}\text { Weighted } \\
\text { frequency }\end{array}$ & $\begin{array}{l}\text { Cumulative } \\
\text { frequency }\end{array}$ & $\begin{array}{l}\text { Weighted } \\
\text { Mean } \\
\text { score }\end{array}$ & $\begin{array}{l}\text { Mean } \\
\text { score } \\
\text { expressed } \\
\text { in \% }\end{array}$ & $\begin{array}{l}\text { Rank } \\
\text { order }\end{array}$ \\
\hline \multirow[t]{3}{*}{1} & High price of & High & 31 & 93 & 93 & 2.25 & 75.00 & I \\
\hline & \multirow{2}{*}{$\begin{array}{l}\text { insecticides/ } \\
\text { pesticides and fun- } \\
\text { gicides }\end{array}$} & Medium & 88 & 176 & 269 & & & \\
\hline & & low & 01 & 01 & 270 & & & \\
\hline \multirow[t]{3}{*}{2} & \multirow{3}{*}{$\begin{array}{l}\text { Non availability of } \\
\text { inputs at proper } \\
\text { time }\end{array}$} & High & 01 & 03 & 03 & 1.13 & 37.77 & II \\
\hline & & Medium & 14 & 28 & 31 & & & \\
\hline & & low & 105 & 105 & 136 & & & \\
\hline \multirow[t]{3}{*}{3} & \multirow{3}{*}{$\begin{array}{l}\text { Non availability of } \\
\text { quality root stocks }\end{array}$} & High & 00 & 00 & 00 & 1.01 & 33.88 & III \\
\hline & & Medium & 02 & 04 & 04 & & & \\
\hline & & low & 118 & 118 & 122 & & & \\
\hline \multirow[t]{3}{*}{4} & \multirow{3}{*}{$\begin{array}{l}\text { Lack of finance for } \\
\text { purchase of inputs }\end{array}$} & High & 00 & 00 & 00 & 1.01 & 33.88 & III \\
\hline & & Medium & 02 & 04 & 04 & & & \\
\hline & & low & 118 & 118 & 122 & & & \\
\hline \multirow[t]{3}{*}{5} & \multirow{2}{*}{$\begin{array}{l}\text { Non availability of } \\
\text { labor/high }\end{array}$} & High & 00 & 00 & 00 & 1.00 & 33.33 & IV \\
\hline & & Medium & 00 & 00 & 00 & & & \\
\hline & labor charges & low & 120 & 120 & 120 & & & \\
\hline
\end{tabular}

\section{RESULTS AND DISCUSSION}

Constraints related to inputs: The results of present study in Table 1 regarding constraints related to input show that 'high price of insecticides/pesticides' ranked first constraint with weighted mean score (2.25), followed by 'non-availability of inputs at proper time' ranked second major constraint with weighted mean score (1.13), whereas 'non-availability of quality rootstocks' and 'lack of finance for purchase of inputs' were ranked third with weighted mean score (1.01). 'Non-availability of labor/high labor charges' was ranked fifth with weighted mean score (1.00).

The finding of present study concluded that high price of insecticides/pesticides and non-availability of inputs at proper time was major input related to constraints. Non-availability of recommended cultivators might have also contributed towards low production and adoption level of masumbi cultivation in state. The study gets support from findings of Biswas and Jamir (2015) who reported that unavailability of quality input material was a serious constraint in kitchen gardening techniques in Mokochung district of Nagaland and Sharma et al. (2011) who highlighted that input constraints were most serious constraint followed by general constraints and technical constraints etc. in kitchen gardening.

Constraints related to marketing: Data presented of present study in the Table 2 it is clear that among constraints related to marketing 'absence of agroprocessing units' ranked first constraint with weighted mean score (2.05), followed by 'no support price' ranked second with weighted mean score (1.86). 'Lack of guidance for proper time and place for marketing' and 'lack of transport facilities and disposal of produce' were ranked third and fourth with weighted mean score (1.20) and (1.00), respectively.

Study revealed that absence of agro processing units and no support price were serious constraints. Findings are in agreement with the Samantaray et al. (2009) who reported that lack of post-harvest technologies as major constraint in vegetable production faced by tribal vegetable growers.

Constraints related to production: Table 3 narrate constraints of present study related to production that 'aberrant climatic conditions' and 'unawareness about proper and balanced fertilizer application and time of application' ranked first constraint with highest weighted mean score (1.99), followed by 'farmer and labor are not skillful due to lack of trainings' ranked second with weighted mean score (1.82). 'Lack of proper cropping sequence followed by farmer' was ranked third with weighted mean score (1.29), by the masumbi growers. The present study also revealed that aberrant climatic condition was major constraint and unawareness about proper and balanced fertilizer application and time of application increased the input cost. Adverse weather condition like heavy rains, wind, hailstorm, etc. damaged the fruit crops to substantial extent every year, which resulted in low production of masumbi due to these natural vagaries. These findings are in conformity with study of Hussen and Yimer (2013) who reported that farmer awareness about spacing of orchards, pruning, fertilizer application, access of new varieties and pest and disease control was very low in mango fruit at Bhati, Oromiya Zone of Ethiopia.

Constraints related to technical guidance: Findings 
Pawan Kumar et al. / J. Appl. \& Nat. Sci. 8 (2): 785 - 789 (2016)

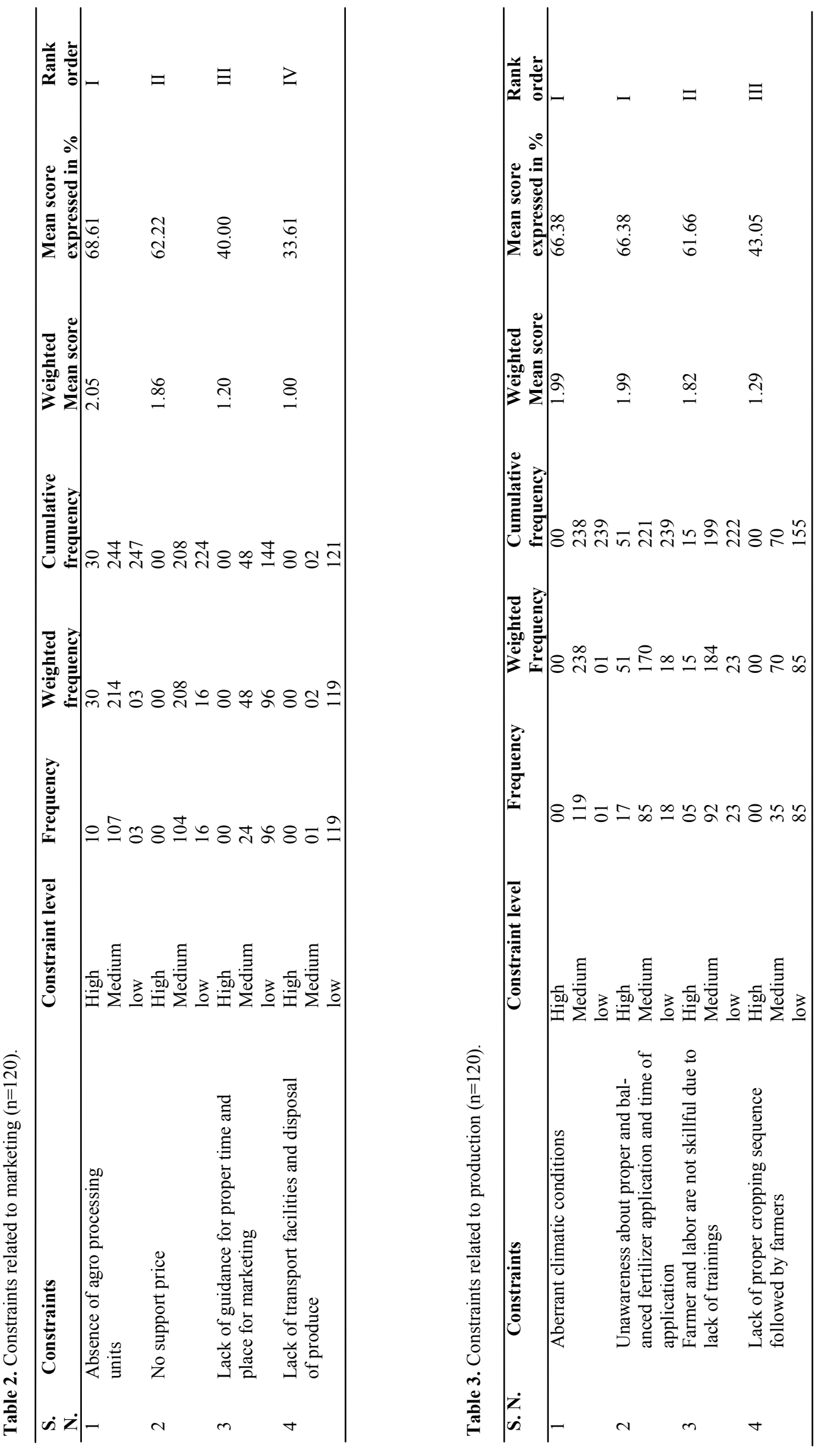




\section{$\mid$}

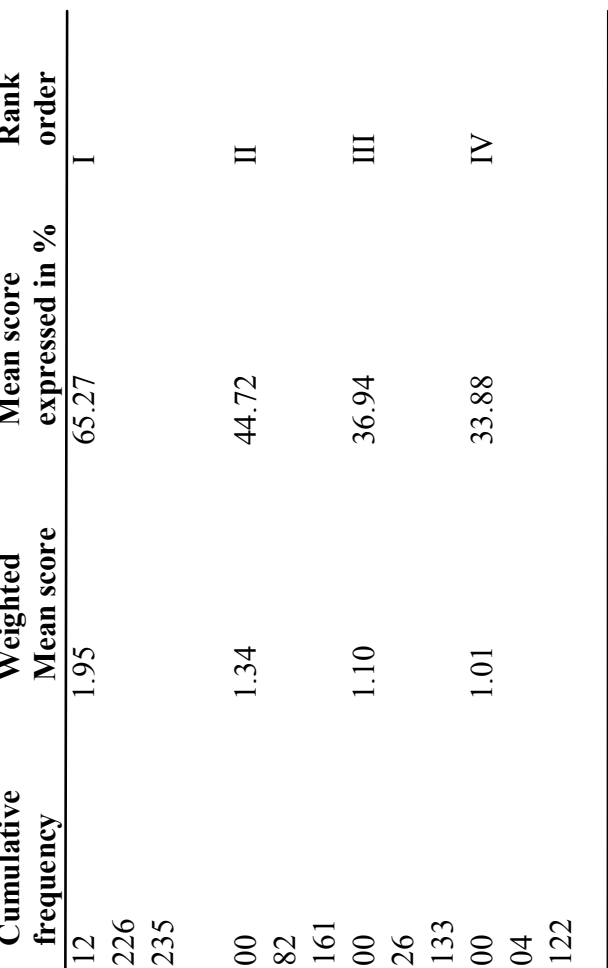

สํำ

\section{)}

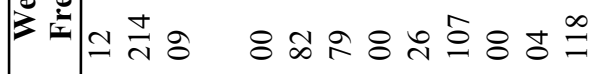

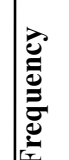

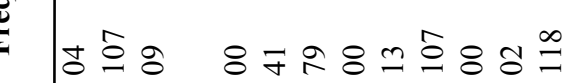

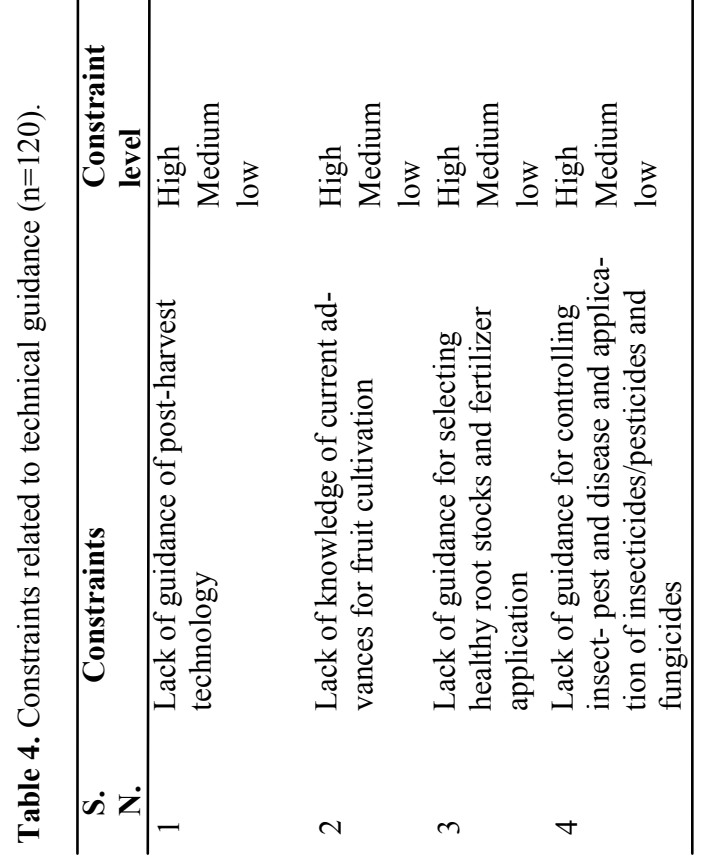

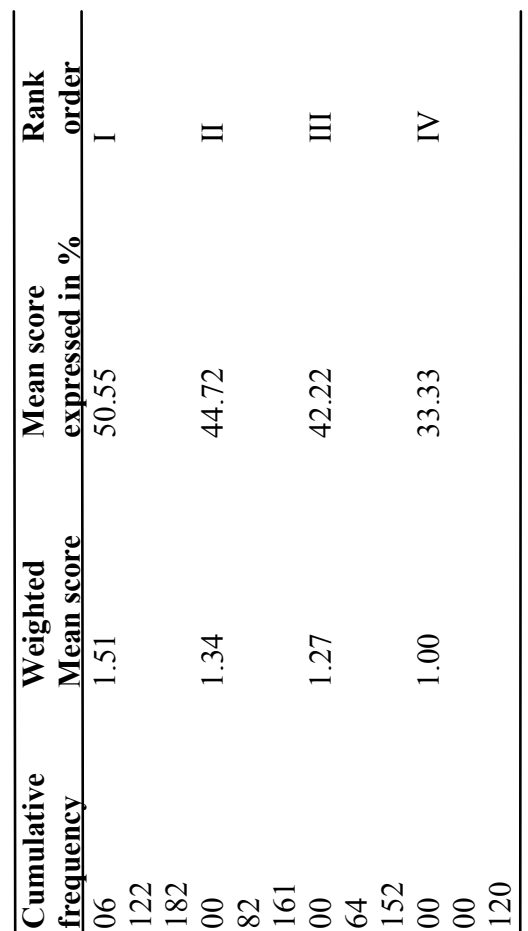

氮

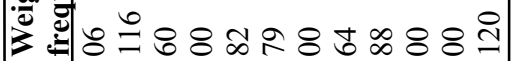

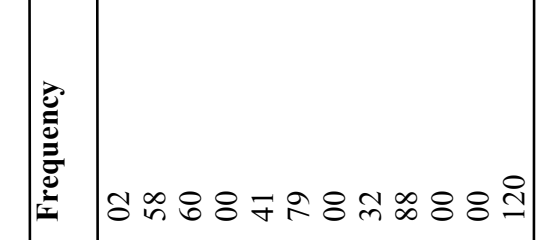

㝏

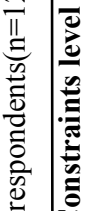

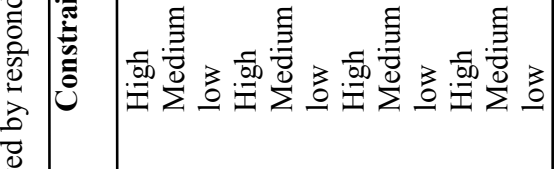


of the present study (Table 4) revealed that constraints related to technical guidance among which 'lack of guidance of post-harvest technology' was considered the most serious constraint by the masumbi growers and ranked first with weighted mean score (1.95), followed by 'lack of knowledge of current advances for masumbi fruit cultivation' ranked second with weighted means score (1.34). 'Lack of guidance for selecting healthy root-stock and fertilizer application' was ranked third with weighted mean score (1.10), followed by 'lack of guidance for controlling insect-pest and diseases and their control' ranking fourth constraint with weighted mean score (1.01).

All these constraints could be minimize by providing training and also by distributing the literature regarding the technical know-how to the farmers as it requires specialized skills in certain operations. ICT facilities can also play great role in mitigating these constraints. These findings are in line with the findings of Choudhary and Bangarwa (2013) who concluded that the constraints most perceived by the farmers in adoption were high initial cost in establishing of orchard, irregular water supply from canal, lack of proper market and lack of need based training in Kinnow production by the farmers of Sri-Ganganagar district of Rajasthan and Singh (2004) reported that inadequate training for technical skills was major constraint in mango fruit production.

Psychological constraints as perceived by respondents: An examination of results of present study in Table 5 indicate that among psychological constraints 'longer time taken in fruit bearing' was a major problem with weighted mean score (1.51), followed by 'orchard maintenance' as second important constraint with weighted mean score (1.34). 'Self-marketing' and 'the notion of more irrigation' were ranked third and fourth with weighted mean scores (1.27) and (1.00), respectively.

Present study also revealed that longer time taken in fruit bearing, maintaining orchard: not an easy task and self-marketing: a problem were major psychological constraints faced by the respondents. These psychological constraints can be mitigated by extension workers, by providing psychological support coupled with latest information of marketing intelligence and credit facilities. Findings are in agreement with the study of Singh et al. (2010) who found that weak extension activities at village level were the major constraint in rice production technology.

\section{Conclusion}

The present study concluded that high price of insecticides/pesticides and non-availability of inputs at proper time was major constraints related to inputs while absence of agro-processing units and no support price were serious constraints pertaining to marketing. In case of constraints related to production, aberrant climatic condition and unawareness about proper and balanced fertilizer application and time of application were important constraints. Lack of guidance of post-harvest technology and lack of knowledge of current advances in fruit cultivation were major technical constraints. Longer time taken in fruit bearing and orchard maintenance etc. were major psychological constraints perceived by masumbi farmers. So, the government should address the problem of better technical support and credit facilities for wider adoption of this fruit crop.

\section{REFERENCES}

Anonymous (2014). National Horticulture Database 201314, National Horticulture Board, Ministry of Agriculture, Govt. of India, Gurgaon.

Biswas, P.K. and Jamir, S. (2015). Constraints faced by farmers an adoption of kitchen gardening techniques in Mokochung district, Nagaland. International Journal of Farm Sciences. 5(3): 207-211.

Choudhary, H.D. and Bangarwa, G.S. (2013). Knowledge and constraints in recommended kinnow production technology among the kinnow growers. International Journal of Agricultural Sciences. 9(2): 472-275.

Hussen, S. and Yimer, Z. (2013). Assement of production potential and constraints of mango at Bhati, Oromiya Zone, Ethiopia. International Journal of Science: Basic and Applied Research. 11(1): 1-9.

Samantaray, S.K., Prusty, S. and Raj, R.K. (2009). Constraints in vegetable production experiences of tribal vegetable growers. Indian Research Journal of Extension Education. 9(3): 32-34.

Sharma, K., Singh, G., Dhaliwal, N.S. and Yadav, Y.P.S. (2011). Constraints in adoption of recommended kitchen gardening techniques. Journal of Community Mobilization and Sustainable Development. 6(1): 96-99.

Singh, M. (2004). Adoption and constraints in mango cultivation. M.Sc.Thesis (unpublished) Department of Ext. Edu., CCSHAU, Hisar.

Singh, P.K., Varshney and Jay, G. (2010). Adoption level and constraints in rice production technology. Indian Research Journal of Extension Education. 10(1): 91-94. 